\title{
Flora da Bahia: Styracaceae
}

\author{
Renata Asprino ${ }^{1,2}$ \& André Márcio Amorim ${ }^{1,2^{*}}$ \\ ${ }^{1}$ Centro de Pesquisas do Cacau, Herbário CEPEC e ${ }^{2}$ Departamento de Ciências Biológicas, Universidade \\ Estadual de Santa Cruz. Ilhéus, Bahia, Brasil.
}

\begin{abstract}
Resumo - É apresentado um levantamento florístico de Styracaceae para o estado da Bahia, Brasil. Foram reconhecidas oito espécies de Styrax no estado. Dentre elas, S. acuminatus representa um novo registro para a região Nordeste. Styrax ferrugineus e S. pedicellatus são conhecidas por coleções escassas, o que sugere uma distribuição restrita a áreas de cerrado e campo rupestre, respectivamente. O tratamento inclui uma chave de identificação, descrições, comentários sobre os táxons, além de ilustrações e mapas de distribuição geográfica das espécies na Bahia.
\end{abstract}

Palavras-chave adicionais: Brasil, florística, Região Nordeste, Styrax, taxonomia.

\begin{abstract}
Flora of Bahia: Styracaceae) - A floristic survey of the Styracaceae from Bahia state, Brazil, is presented. Eight species of Styrax were recognized, among which S. acuminatus represents a new record for the Northeastern region of Brazil. Styrax ferrugineus and S. pedicellatus are registered from few specimens, which suggest restricted distributions in cerrado and campo rupestre areas, respectively. The treatment includes a key to identification, descriptions and comments on taxa, as well as illustrations and geographic distribution maps of species in Bahia.
\end{abstract}

Additional key words: Brazil, floristics, Northeastern Region, Styrax, taxonomy.

\section{STYRACACEAE}

Árvores, arvoretas ou arbustos, tricomas estrelados ou escamas. Estípulas ausentes. Folhas perenes ou decíduas, simples, alternas, pecioladas, margem inteira ou serreada, peninérvias. Inflorescências axilares ou pseudoterminais, cimosas, racemosas, fasciculadas ou flores solitárias. Flores actinomorfas, hipanto adnato ao ovário em vários graus; cálice gamossépalo, (2-)4 ou 5(-9)-denteado ou -lobado; corola gamopétala, 4 ou 5(-8)-lobada, prefloração imbricativa ou valvar; estames o dobro ou em número igual aos lobos da corola, epipétalos, anteras oblongas a lineares, basifixas, bitecas, deiscência longitudinal, introrsa; ovário súpero ou ínfero, 2-4(5)-carpelar, 2-4(5)-septado proximalmente, 1-locular por atenuação distal do septo, (1-)4-9(-numerosos) óvulos por carpelo, placentação axial ou basal, estilete filiforme, estigma truncado ou lobado. Frutos deiscentes (cápsula loculicida) ou indeiscentes (baga, cápsula, drupa ou sâmara), com cálice persistente. Sementes 1-4(-numerosas), subglobosas a elipsoides ou fusiformes.

Styracaceae está incluída na ordem Ericales (APG III 2009) e possui 11 gêneros e aproximadamente 160 espécies (Fritsch 2004a). Apresenta uma distribuição disjunta, em áreas temperadas e tropicais das Américas, sul da Europa e leste e sudeste da Ásia (Fritsch et al. 2001). No Brasil, ocorre apenas o gênero Styrax L.

\footnotetext{
*Autor para correspondência: amorim.uesc@gmail.com Editor responsável: Luciano Paganucci de Queiroz Submetido: 20 jan. 2013; aceito: 12 jul. 2013

Publicação inicial: 30 dez. 2013; versão final: 2 maio 2014
}

\section{Styrax L.}

Árvores, arvoretas ou arbustos, tricomas estrelados, raramente escamas. Folhas perenes, margem inteira, nervação broquidódroma ou inconspicuamente eucamptódroma. Inflorescências axilares e/ou pseudoterminais, racemosas, bracteoladas. Flores com hipanto adnato ao ovário somente na base; cálice cupuliforme, 5-denteado; corola 5-lobada, pétalas conatas na base, prefloração valvar; estames 5 ou 10, filetes achatados, conatos entre si e adnatos à corola, pubescentes ou glabros, conectivos glabros, anteras pubescentes ou glabras; ovário súpero, 3-carpelar, 3-septado proximalmente, mas 1-locular por atenuação distal do septo, 1-8 óvulos por carpelo; estilete glabro, estigma trilobado. Frutos drupáceos. Sementes 1(2), subglobosas, elipsoides ou fusiformes.

Styrax é o maior gênero de Styracaceae, com ca. 130 espécies e distribuição geográfica coincidente à da família. Cerca de 37 espécies são encontradas no leste e sudeste da Ásia, uma espécie na região Mediterrânea e cerca de 82 no continente americano, desde os Estados Unidos até a Argentina (Fritsch 1999; Fritsch et al. 2001). A descrição genérica aqui apresentada está baseada em caracteres morfológicos das espécies de Styrax seção Valvatae P.W.Fritsch série Valvatae, endêmica da região Neotropical.

No Brasil, ocorrem 24 espécies, com representantes em quase todos os estados, distribuídos em diversos domínios fitogeográficos (Fritsch 2012). Na Bahia, foram encontradas oito espécies. 


\section{Chave de identificação}

1. Flores com 5 estames; ovário triovulado; pétalas 4,5-5 $\mathrm{mm}$ compr. 6. S. pedicellatus

1'. Flores com 10 estames; ovário com mais de 3 óvulos; pétalas 9,5-20 mm compr.

2. Face abaxial das folhas glabra ou com tricomas estrelados esparsos 4. S. glabratus

2'. Face abaxial das folhas densamente estrelado-tomentosa.

3. Fruto 17-18 mm compr., elipsoide; lâmina foliar subcartácea; planta de floresta ombrófila densa

1. S. acumind

3'. Fruto 6-11 mm compr., globoso a subgloboso; lâmina foliar cartácea a coriácea; planta de cerrado e formações campestres.

4. Face adaxial das folhas com tricomas estrelados esparsos, inclusive nas folhas mais velhas 5. S. griseus

4'. Face adaxial das folhas glabra, pelo menos nas folhas mais velhas.

5. Folhas com face abaxial ferrugínea, raio dos tricomas $0,15-0,2 \mathrm{~mm}$, lâmina subcoriácea a coriácea, 2,5-6,7 cm compr., comumente suborbiculada a ovada; ovário ca. 1,5 mm larg.

8.S. rotundatus

5'. Folhas com face abaxial castanha ou acinzentada, raio dos tricomas $0,3-0,9 \mathrm{~mm}$, lâmina cartácea a subcoriácea, $6-12 \mathrm{~cm}$ compr., estreita a largamente elíptica ou ovada; ovário 2-2,5 $\mathrm{mm}$ larg.

6. Face abaxial das folhas com indumento heterogêneo: tricomas ferrugíneos maiores esparsos sobre indumento denso de tricomas cinéreos menores; planta geralmente de ambientes úmidos

6'. Face abaxial das folhas com indumento de tricomas cinéreos ou castanhos de tamanho uniforme; planta de ambientes relativamente secos.

7. Face abaxial das folhas maduras cinérea, às vezes com tricomas castanhos ou amarelados nas nervuras, nervuras quaternárias impressas, raio dos tricomas $0,3-0,6 \mathrm{~mm}$

2. S. camporum

7'. Face abaxial das folhas maduras castanha, nervuras quaternárias salientes, raio dos tricomas $0,7-0,9 \mathrm{~mm}$

3. S. ferrugineus

1. Styrax acuminatus Pohl, Pl. Bras. Icon. Descr. 2: 58. 1830.

Figuras $1 \mathrm{~A}-\mathrm{C}$ e 2.

Árvores, ca. $15 \mathrm{~m}$ alt.; ramos estrelado-tomentosos, castanho-claros quando jovens. Folhas com pecíolo 6,5-10 mm compr.; lâmina 6-8,5(-10,5) × 2,5-3,6 cm, subcartáceas, discolor, ovada ou elíptico-lanceolada, base aguda ou cuneada, ápice acuminado ou atenuado, margem plana, nervuras primárias e secundárias salientes, terciárias levemente salientes, quaternárias impressas, face abaxial densamente estreladotomentosa, cinérea, nervuras castanhas, com tricomas marrons ou amarelados adensados nas nervuras e esparsos na lâmina sobre indumento denso de tricomas cinéreos, raio dos tricomas $0,1-0,15 \mathrm{~mm}$, face adaxial glabrescente. Inflorescências 1,5-3,5 cm, com 1-5 flores, raque marrom; pedicelo $3,5-5 \mathrm{~mm}$. Flores $1-1,2 \mathrm{~cm}$ compr.; cálice 2,5-3,5 $\times$ 3-3,5 $\mathrm{mm}$, castanhoamarelado, com tricomas amarelos e marrons sobre indumento de tricomas cinéreos; pétalas 11-11,5 × ca. $1,5 \mathrm{~mm}$; estames $10,8,5-9,5 \mathrm{~mm}$ compr., filetes pubescentes, anteras ca. $6 \mathrm{~mm}$ compr., pubescentes; ovário ca. 1,5 mm larg., óvulos numerosos, estilete ca. $8 \mathrm{~mm}$ compr. Drupas $17-18 \times 10-11 \mathrm{~mm}$, elipsoides, envolvidas até ca. $1 / 5$ pelo cálice.

Ocorre no Uruguai (Perkins 1907) e no Brasil em todos os estados da região Sul, São Paulo, Rio de Janeiro (Fritsch 2012) e Bahia. G8: floresta ombrófila densa montana e submontana. Coletada com flores em novembro e com frutos em agosto.
Material examinado - Almadina, Serra do Corcovado, 14 $42^{\prime} 09^{\prime \prime S}, 39^{\circ} 36^{\prime} 14^{\prime \prime W}, 600-850$ m s.n.m., 5 nov. 2011 (fl.), M.M. Coelho et al. 494 (CEPEC); Ubatã, 14'12'55"S, 39³1'22"W, 109 m s.n.m., 25 ago. 1964 (fr.), C.M.M. 222 (CEPEC).

Material adicional - BRASIL. RIO DE JANEIRO: Rio de Janeiro, Estrada do Redentor, 22 ${ }^{\circ} 54^{\prime} 10^{\prime \prime} \mathrm{S}, 43^{\circ} 12^{\prime} 27^{\prime \prime} \mathrm{W}, 2$ set. 1959 (fl.), A.P. Duarte 5005 (CEPEC, HUEFS, RB). SANTA CATARINA: Itajaí, Morro da Fazenda, 265'ㄹ"'S, 48 39'43"W, 350 m, 7 jan. 1955 (fr.), R.M. Klein 1019 (R).

Styrax acuminatus pode ser caracterizada pelas folhas com lâmina subcartácea, ovada ou elípticolanceolada com ápice acuminado ou atenuado, discolores, face abaxial com indumento de tricomas marrons esparsos sobre indumento denso de tricomas cinéreos e drupas elipsoides com 17-18 mm compr. Este trabalho aponta a primeira ocorrência de S. acuminatus na Região Nordeste.

2. Styrax camporum Pohl, Pl. Bras. Icon. Descr. 2: 53. 1830.

Figuras 1D-H e 2.

Árvores, arvoretas ou arbustos, 1-8 m alt.; ramos estrelado-tomentosos, castanho-claros quando jovens. Folhas com pecíolo $7-10(-13) \mathrm{mm}$ compr.; lâmina $6-10 \times 2,5-5(-6,4) \mathrm{cm}$, cartácea a subcoriácea, discolor, estreita a largamente elíptica ou ovada, base obtusa, arredondada ou cuneada, ápice levemente acuminado, agudo ou obtuso, margem plana, nervuras primárias e secundárias salientes, terciárias levemente salientes, quaternárias impressas, face abaxial 
densamente estrelado-tomentosa, cinérea ou castanha quando jovem, posteriormente cinérea, às vezes com tricomas amarelos ou castanhos nas nervuras, raio dos tricomas $0,3-0,6 \mathrm{~mm}$, face adaxial glabrescente. Inflorescências $2,3-6 \mathrm{~cm}$, com 3-10(-12) flores, raque castanha ou cinéreo-esverdeada; pedicelo 4-8(-10) $\mathrm{mm}$. Flores 1,1-1,5 cm compr.; cálice 3-4,6 × 3,5-4,5 mm, cinéreo-esverdeado, tricomas cinéreos; pétalas 10-14,5 $\times$ 2-2,5 mm; estames 10, (9-)11-13 mm compr., filetes pubescentes, anteras 5,5-6 $\mathrm{mm}$, compr. pubescentes; ovário 2-2,5 $\mathrm{mm}$ larg., óvulos numerosos, estilete $(8,5-) 9,5-12 \mathrm{~mm}$. Drupas 7-8 × 6-8 mm, globosas a subglobosas, envolvidas até ca. $1 / 2$ pelo cálice.

Ocorre no Paraguai e no Brasil, em toda a região Centro-Oeste e nos estados do Ceará, Pernambuco, Bahia, Minas Gerais, Espírito Santo, São Paulo e Paraná (Loeuille et al. 2008, Fritsch 2012). C7, D6, D7, E6, E7, F5, F6, F7, G5, G6, J8: cerrado, campo rupestre, floresta estacional semidecidual e campos arenosos em restinga. Coletada com flores de janeiro a agosto e em dezembro e com frutos de março a novembro.

Material selecionado - Abaíra, Catolés, 1318'15"S, 4151'57"W, 1165-1205 m s.n.m., 4 fev. 2003 (fl.), F. França et al. 4296 (HUEFS); Andaraí, rodovia para Itaetê, $12^{\circ} 51^{\prime} \mathrm{S}, 41^{\circ} 12^{\prime} \mathrm{W}$, 500-600 m s.n.m., 13 fev. 1977 (fl.), R.M. Harley 18629 (CEPEC);

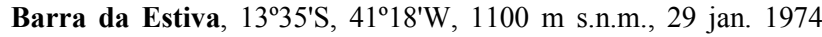
(fl.), R.M. Harley 15656 (CEPEC, RB); Brumado, Serra das Éguas,

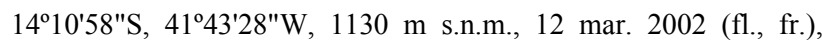
H.P. Bautista et al. 3207 (HUEFS); Caetité, Serra Geral, 1404'S, 42²8'W, 824 m s.n.m., 10 fev. 1998 (fl.), M.L. Guedes et al. 7668 (ALCB, CEPEC); Campo Formoso, Morro do Cruzeiro, 10 30 'S, 40²0'W, 556 m s.n.m., 31 jan. 1993 (fl.), W. Thomas et al. 9665 (CEPEC); Caravelas, rodovia para Teixeira de Freitas, 17\%43'55"S, 39²15'57"W, 10 m s.n.m., 10 ago. 1972 (fl.), T.S. Santos 2344 (CEPEC); Érico Cardoso, Morro do Fogo, 13⒉1'14"S, 42 $05^{\prime} 46 " \mathrm{~W}, 1126$ m s.n.m., 14 jan. 2008 (fl.), A. Rapini 1516 (HUEFS); Jacobina, Serra do Tombador, $11^{\circ} 09^{\prime} 10^{\prime \prime} \mathrm{S}, 40^{\circ} 29^{\prime} 10^{\prime \prime} \mathrm{W}$, 950 m s.n.m., 8 abr. 2001 (fl.), T. Ribeiro et al. 196 (ALCB, CEPEC, HUEFS, HUESC); Maracás, estrada do cruzeiro, 13²4'16"S, 40²6'40"W, 972 m s.n.m., 23 abr. 2002 (fl.), E.R. Souza et al. 194 (HUEFS); Miguel Calmon, Piemonte da

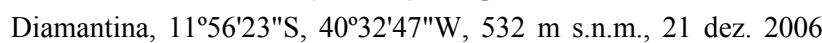
(fl.), M.L. Guedes et al. 13040 (ALCB); Mirangaba, Caboré, $10^{\circ} 55^{\prime} \mathrm{S}, \quad 40^{\circ} 40^{\prime} \mathrm{W}, \quad 829 \mathrm{~m}$ s.n.m., 01 set. 1981 (fr.), L.M.C. Gonçalves 173 (CEPEC, RB); Morro do Chapéu, estrada

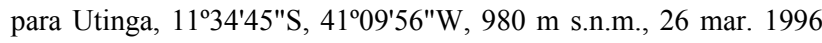
(fl., fr.), M.L. Guedes et al. 2571 (ALCB, HUEFS); Mucugê, estrada para Guiné, $12^{\circ} 53^{\prime} 06^{\prime \prime} \mathrm{S}, 41^{\circ} 31^{\prime} 43^{\prime \prime} \mathrm{W}, 1071 \mathrm{~m}$ s.n.m., 29 out. 2005 (fr.), J.G. Carvalho-Sobrinho \& A.J. Neto 695 (HUEFS); Palmeiras, Morro do Pai Inácio, 12²6'12"S, 41²9'14"W, $720 \mathrm{~m}$ s.n.m., 1 jul. 1995 (fr.), M.L. Guedes et al. 2128 (ALCB, CEPEC, HRB, HUEFS); Piatã, Malhada do Baixo de Areia, 130.'43"S,

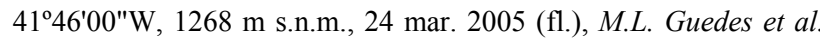
11716 (ALCB); Rio de Contas, Brumadinho, 1331'18"S, 415'02"W, 1278 m s.n.m., 11 jun. 2004 (fr.), M.N.S. Stapf 320 (CEPEC, HUEFS, RB); Rio do Pires, riacho da Forquilha, 135ㄴ' $\mathrm{S}$,

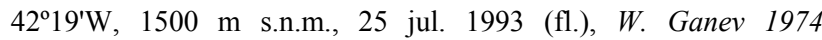

(HUEFS); Ruy Barbosa, Serra do Orobó, $12^{\circ} 18^{\prime} 52^{\prime \prime} \mathrm{S}, 40^{\circ} 29^{\prime} 37^{\prime \prime} \mathrm{W}$, 616 m s.n.m., 25 mar. 2005 (fl.), D. Cardoso et al. 335 (CEPEC, HUEFS); Seabra, Serra do Bebedor, $12^{\circ} 25^{\prime} 07^{\prime \prime S}, 41^{\circ} 46^{\prime} 13^{\prime \prime W}, 812$ m s.n.m., 15 nov. 1983 (fr.), H.P. Bautista et al. 1265 (ALCB, CEPEC, HUEFS); Senhor do Bonfim, Varzinha, 10²9'23"S, $40^{\circ} 14^{\prime} 28^{\prime \prime} \mathrm{W}, 743$ m s.n.m., 30 out. 2005 (fr.), S.F. Conceição et al. 288 (HUEFS).

Styrax camporum pode ser caracterizada por apresentar folhas cartáceas a subcoriáceas, discolores, com indumento da face abaxial cinéreo, formado por tricomas com raio $0,3-0,6 \mathrm{~mm}$, aveludadas ao toque. Assemelha-se morfologicamente a $S$. griseus mas suas áreas de ocorrência na Bahia se mostram distintas. Uma discussão mais detalhada sobre as afinidades morfológicas dessas espécies é apresentada no comentário de $S$. griseus.

3. Styrax ferrugineus Nees \& Mart., Nov. Acta Acad. Caes. Leop. Carol. Nat. 11(1): 88. 1823.

Figuras 1I-J e 2.

Arvoretas ou arbustos, ca. $2 \mathrm{~m}$ alt.; ramos estrelado-tomentosos, castanhos a ferrugíneos quando jovens. Folhas com pecíolo 9-14 mm compr.; lâmina 7-12 × 4-6 cm, cartácea a subcoriácea, discolor, estreita a largamente elíptica ou ovada, base obtusa, arredondada ou cuneada, ápice agudo a levemente acuminado, margem plana, nervuras primárias a quaternárias salientes, face abaxial densamente estrelado-tomentosa, lâmina e nervuras castanhas, tricomas cinéreos ou castanhos a ferrugíneos, raio dos tricomas $0,7-0,9 \mathrm{~mm}$, face adaxial glabrescente. Inflorescências 3,5-5 cm, com 3-9 flores, raque castanha a ferrugínea; pedicelo 4-5(-9) $\mathrm{mm}$ compr. Flores 1,2-1,5 cm compr.; cálice 3-4,8 × 3,4-4,7 mm, cinéreo-esverdeado ou amarelado a castanho, tricomas cinéreos, castanhos ou dourados; pétalas 10-15,5 × 2-2,2 $\mathrm{mm}$; estames 10, 10-12 mm compr., filetes pubescentes, anteras 5,5-6 $\mathrm{mm}$ compr., pubescentes; ovário 2-2,5 $\mathrm{mm}$ larg., óvulos numerosos, estilete 8,5-10 mm compr. Drupas 9-11 × 5-6 mm, globosas a subglobosas, envolvidas até ca. $1 / 2$ pelo cálice.

Ocorre no Paraguai, Bolívia (Loeuille et al. 2008) e Brasil, em todos os estados do Centro-Oeste, Rondônia, Minas Gerais, São Paulo, Paraná (Fritsch 2012), Espírito Santo e Bahia (Perkins 1907; Loeuille et al. 2008). G2: cerrado. Coletada com flores em dezembro.

Material examinado - Côcos, fazendas Trijunção, 14'53'12"S, 4551'59"W, 860 m s.n.m., 11 dez. 2001 (fl.), M.L. Fonseca et al. 3070 (HRB, RB).

Material adicional examinado - BRASIL. DISTRITO FEDERAL: Gama, DF-016 3 a 7 km da junção com a BR-040, $15^{\circ} 58^{\prime} \mathrm{S}, 48^{\circ} 02^{\prime} \mathrm{W}, 1100$ m s.n.m., 10 jul. 1984 (fl., fr.), S.A. Mori et al. 16657 (CEPEC).

Styrax ferrugineus assemelha-se a $S$. camporum pelas folhas estreito a largamente elípticas ou ovadas e flores com cálice frequentemente cinéreo-esverdeado. Porém, diferencia-se desta por apresentar a face abaxial das folhas castanha (vs. cinérea), com as nervuras 

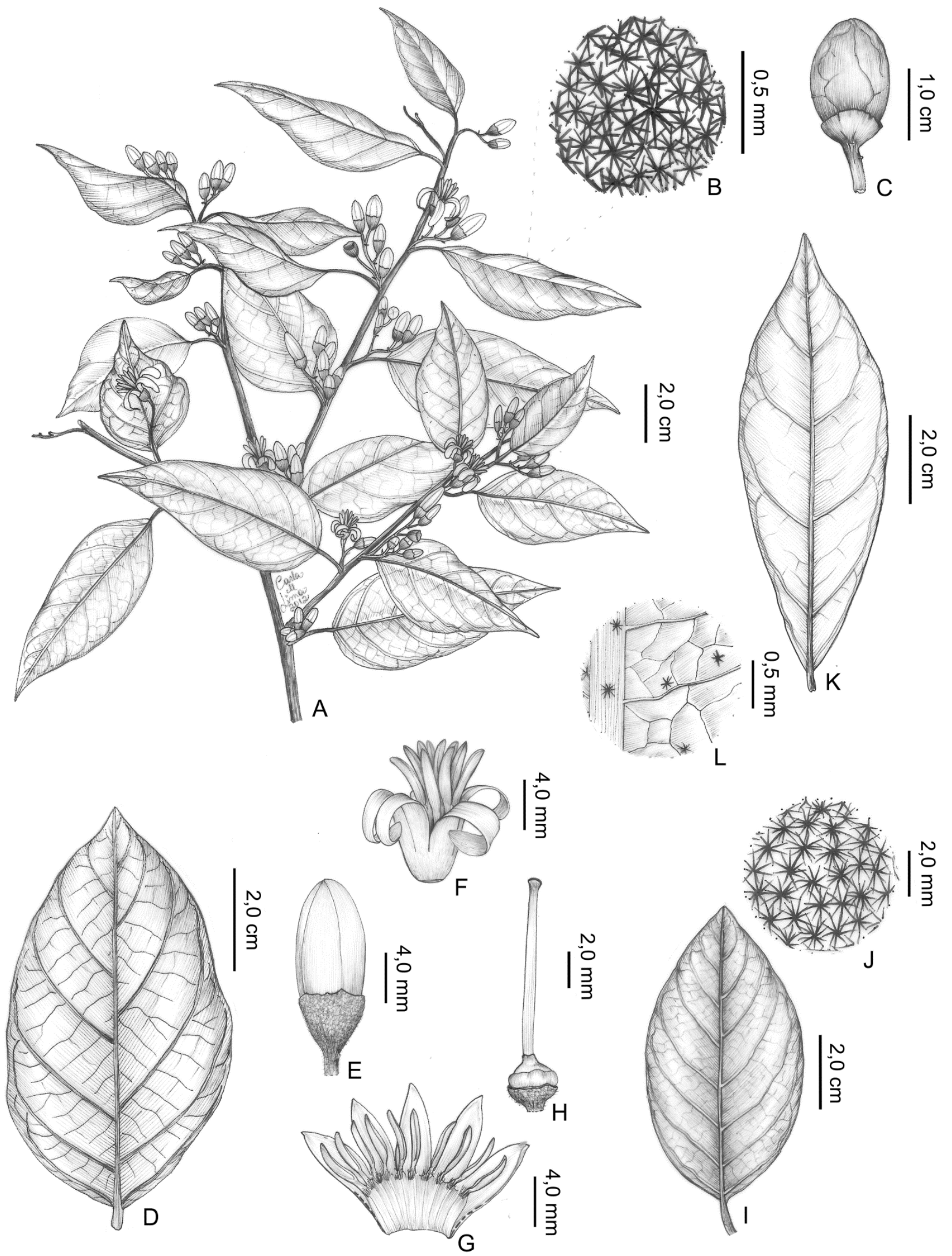

Figura 1. A-C. Styrax acuminatus: A- ramo com flores; B- detalhe do indumento da folha, face abaxial; C- fruto maduro, vista lateral. D-H. Styrax camporum: D- folha, face abaxial; E- botão, vista lateral; F- corola e estames; G- corola distendida com estames adnatos, vista abaxial; H- pistilo. I-J. Styrax ferrugineus: I- folha, face abaxial; J- detalhe do indumento da folha, face abaxial. K-L. Styrax glabratus: K- folha, face abaxial; L- detalhe do indumento da folha, face abaxial. (A- Coelho 494; B- Duarte 5005; C- C.M.M. 222; D- CarvalhoSobrinho 695; E-H- Meireles 703; I-J- Amorim 1409; K-L- Fonseca 3070). 


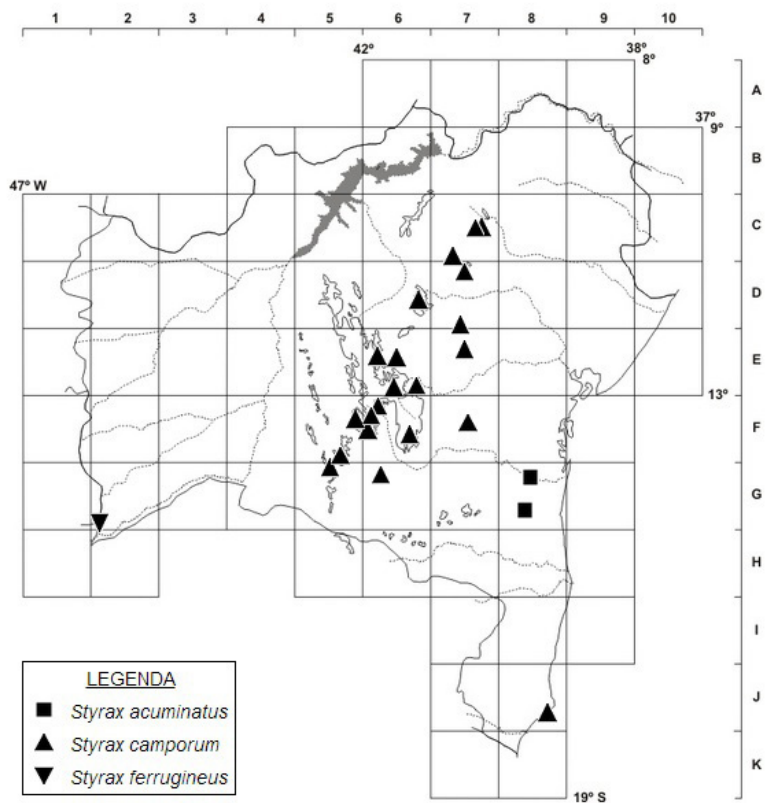

Figura 2. Distribuição geográfica de Styrax acuminatus, $S$ camporum e $S$. ferrugineus no estado da Bahia.

4. Styrax glabratus Schott, Syst. Veg. 4(2): 406. 1827. Figuras $1 \mathrm{~K}-\mathrm{L}$ e 3.

Árvores, arvoretas ou arbustos, 2,4-7 m alt.; ramos estrelado-tomentosos, marrons ou acinzentados quando jovens. Folhas com pecíolo (7-)9-11(-14) $\mathrm{mm}$ compr.; lâmina $(7,8-) 9,8-18,8 \times(3-) 3,8-6,6 \mathrm{~cm}$, papirácea ou cartácea, concolor, elíptica a oblonga ou oblanceolada, base cuneada, obtusa ou arredondada, ápice agudo ou acuminado, margem plana ou levemente revoluta, nervuras primárias e secundárias salientes, terciárias levemente salientes, quaternárias impressas ou levemente salientes, face abaxial glabrescente, com tricomas estrelados cinéreos a amarelados apenas nas nervuras, ou pubescente, com tricomas cinéreos esparsos, raio dos tricomas $0,15-0,8 \mathrm{~mm}$, face adaxial glabra. Inflorescências $2-3,8(-5) \mathrm{cm}$, com 2-6(-10) flores, raque amarela a castanha ou cinéreo-esverdeada; pedicelo (3-)4-7,5(-12) mm compr. Flores (1,2-)1,5-2,1 cm compr.; cálice (3-)4-9 × (2,5-)3-7 mm, amarelado ou cinéreo-esverdeado, tricomas castanhos ou cinéreos; pétalas $17-18,5(-20) \times$ (1,5-)2-3,5 mm; estames 10, 13,5-16 mm compr., filetes pubescentes, anteras $(5,5-) 6,5-7,5 \mathrm{~mm}$ compr., pubescentes; ovário (2-)2,5-3 $\mathrm{mm}$ larg., óvulos numerosos, estilete 13,5-15,5 mm compr. Drupas $15-18 \times(7-) 8-10 \mathrm{~mm}$, elipsoides, envolvidas $1 / 5$ a $1 / 2$ pelo cálice.

Ocorre na Costa Rica, Colômbia, Guiana Francesa, Suriname e Venezuela (Fritsch 1997). No Brasil, é encontrada em alguns estados das Regiões Norte e Sul, em todos os estados do Sudeste e na Bahia (Fritsch 2012), sugerindo assim uma distribuição disjunta entre o bloco florestal amazônico e a Floresta Atlântica. F8, G8, H8, I8: floresta ombrófila densa submontana e restinga. Coletada com flores em janeiro, maio e outubro, e com frutos em junho e setembro.
Material selecionado - Camamu, rodovia a Travessão Km 33, $14^{\circ} 00^{\prime} \mathrm{S}, 39^{\circ} 13^{\prime} \mathrm{W}, 40$ m s.n.m., 15 jun. 1979 (fr.), L.A. Mattos Silva et al. 507 (CEPEC); Itacaré, ramal da barragem, $14^{\circ} 16^{\prime} 39^{\prime \prime} \mathrm{S}$, 38 59'48"W, 29 m s.n.m., 17 out. 1968 (fl.), J. Almeida \& T.S. Santos 172 (CEPEC); Santa Cruz Cabrália, fazenda Aida Hartman, $16^{\circ} 16^{\prime} 41^{\prime \prime S}, 39^{\circ} 01^{\prime} 29^{\prime \prime W}$, 30-50 m s.n.m., 14 out. 1983 (fl.), G. Martinelli \& T. Soderstrom 9654 (CEPEC, RB); Una, REBIO de Una, $15^{\circ} 17^{\prime} 36^{\prime \prime S}, 39^{\circ} 04^{\prime} 31^{\prime \prime} \mathrm{W}, 28 \mathrm{~m}$ s.n.m., 1 maio 2000 (fl.), J.G. Jardim et al. 3045 (CEPEC); Valença, RPPN Água Branca, $13^{\circ} 19^{\prime} 44^{\prime \prime S}, 39^{\circ} 05^{\prime} 25^{\prime \prime W}, 220$ m s.n.m., 04 set. 2004 (fr.), P. Fiaschi et al. 2509 (CEPEC).

Em Styrax glabratus, foi encontrada uma ampla variação morfológica, fato incomum para as demais espécies do gênero. Foram incluídos no conceito de espécie aqui adotado os espécimes cujas folhas apresentam 7,8-18,8 cm compr., textura papirácea ou cartácea, concolores quando desidratadas, com a face abaxial glabrescente ou pubescente com indumento de tricomas cinéreos esparsos. Verifica-se também espécimes que apresentam domácias nas axilas das nervuras secundárias, mas esse caráter não se mostra constante na espécie. Entretanto, é necessário um estudo abrangente sobre as variações morfológicas da mesma, visto que possui uma distribuição ampla, alcançando a América Central e diversos países da América do Sul.

\section{Styrax griseus P.W.Fritsch, Novon14: 43. 2004.}

Figuras 3 e $4 \mathrm{~A}-\mathrm{C}$.

Arvoretas ou arbustos, 1-2,8 $\mathrm{m}$ alt.; ramos estrelado-tomentosos, castanhos quando jovens. Folhas com pecíolo 5-7(-10) $\mathrm{mm}$ compr.; lâmina $4,5-8,2 \times 2,2-3,9 \mathrm{~cm}$, cartácea a subcoriácea, discolor, elíptica a estreito-elíptica ou ovada, base aguda ou obtusa, ápice agudo a atenuado, margem revoluta, nervuras primárias e secundárias salientes, terciárias levemente salientes, quaternárias impressas, face abaxial densamente estrelado-tomentosa, cinérea, nervuras castanhas, com tricomas castanhos adensados nas nervuras e esparsos na lâmina sobre indumento denso de tricomas cinéreos, raio dos tricomas $0,1-0,12 \mathrm{~mm}$, face adaxial pubescente, com tricomas estrelados cinéreos ou castanhos esparsos. Inflorescências $2-3,5 \mathrm{~cm}$, com 2-6 flores, raque castanha; pedicelo $2,5-3(-4,5)$ $\mathrm{mm}$ compr. Flores 1,1-1,4 cm compr.; cálice 3-4 $\times$ 2,5-3,5 mm, cinéreo-esverdeado, tricomas cinéreos; pétalas $11-11,5 \times$ ca. $1,5 \mathrm{~mm}$; estames $10,8,5-9,5 \mathrm{~mm}$ compr., filetes pubescentes, anteras 5,5-6 mm compr., pubescentes; ovário ca. $1,5 \mathrm{~mm}$ larg., óvulos numerosos, estilete ca. $8 \mathrm{~mm}$ compr. Drupas 6-9 $\times$ 5-6 mm, globosas, envolvidas até ca. $1 / 2$ pelo cálice.

Styrax griseus ocorre nos estados do Pará, Rondônia, Mato Grosso e Bahia (Fritsch 2004b, 2012). C2, E2, F5: cerrado. Coletada com flores em março e abril e com frutos em abril e agosto.

Material selecionado - Formosa do Rio Preto, estrada para Coaceral, 1053'23"S, 45¹4'46"W, 737 m s.n.m., 28 mar. 2000 (fl.), R.M. Harley et al. 53745 (ALCB, CEPEC, HUEFS, HUESC); Igaporã, trevo para Tanque Novo, $13^{\circ} 46^{\prime} 24^{\prime \prime S}, 42^{\circ} 42^{\prime} 24^{\prime \prime} \mathrm{W}, 950 \mathrm{~m}$ 
s.n.m., 18 mar. 1995 (fl.), G.M. Hatschbach 62031 (parátipo

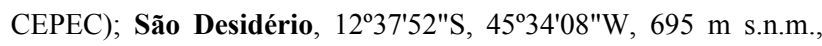
25 abr. 1998 (fr.), M.L.M. Azevedo et al. 1356 (RB).

Styrax griseus assemelha-se a $S$. camporum pelas folhas cartáceas a subcoriáceas, fortemente discolores, com a face abaxial cinérea e o cálice cinéreoesverdeado. Porém, diferencia-se por apresentar folhas com margem revoluta (vs. plana), indumento abaxial heterogêneo, com tricomas castanhos esparsos sobre indumento de tricomas cinéreos (vs. indumento abaxial homogêneo com predominância de tricomas cinéreos), tricomas com raio $0,1-0,12 \mathrm{~mm}$ (vs. $0,3-0,6 \mathrm{~mm}$ ), sendo ásperas ao toque (vs. aveludadas ao toque) e face adaxial pubescente com tricomas cinéreos esparsos (vs. face adaxial glabrescente).

Uma espécie que, segundo a Lista de Espécies da Flora do Brasil, ocorreria na Bahia (Fritsch 2012), Styrax pallidus A.DC., não foi detectada nesse trabalho. Este registro pode ser devido a um espécime de $S$. griseus erroneamente identificado, depositado no herbário NY.

6. Styrax pedicellatus (Perkins) B.Walln., Ann. Naturhist. Mus. Wien 99B: 706. 1997.

Figuras 3 e 4D-G.

Árvores, 3-4 m alt.; ramos estrelado-tomentosos, castanhos a ferrugíneos ou dourados quando jovens. Folhas com pecíolo 5-8(-10) $\mathrm{mm}$; lâmina 4,5-6,2 $\times$ $2-2,7 \mathrm{~cm}$, coriácea, discolor, elíptica a estreito-elíptica, base aguda a cuneada, ápice agudo, obtuso ou arredondado, margem revoluta, nervuras primárias a quaternárias salientes, face adaxial glabrescente, face abaxial densamente estrelado-tomentosa, cinérea, posteriormente acinzentada, nervuras cinéreas ou amareladas com tricomas cinéreos e às vezes dourados esparsos na lâmina e nervuras, raio dos tricomas ca. $0,3 \mathrm{~mm}$. Inflorescências 1,5-5,2 cm, com 6-20 flores, raque cinéreo-esverdeada, amarelada ou castanha; pedicelo 2-3 mm compr. Flores $0,45-0,65 \mathrm{~cm}$ compr.; cálice $2-2,5 \times 3-3,5 \mathrm{~mm}$, cinéreo-esverdeado a amarelado; pétalas 4,5-5 × 1,5-2 mm; estames 5(-6), 3-3,5 mm compr., filetes glabros, anteras ca. $1,5 \mathrm{~mm}$ compr., glabras; ovário 1-1,5 mm larg., triovulado, estilete $2,5-3 \mathrm{~mm}$. Drupas 5-7 × 5-6 mm, globosas a subglobosas, envolvidas até ca. $1 / 3$ pelo cálice.

Styrax pedicellatus ocorre em Minas Gerais e Bahia (Wallnöfer 1997; Fritsch 2012). F6: campo rupestre. Coletada com flores em fevereiro, abril e novembro.

Material examinado - Rio de Contas: Pico das Almas,

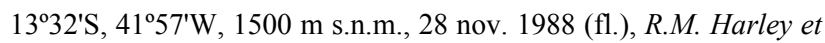

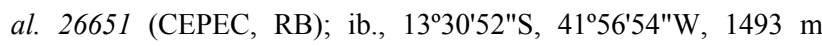
s.n.m., 23 fev. 2004 (fl.), R.M. Harley et al. 54932 (HUEFS).

Material adicional examinado - BRASIL. MINAS GERAIS: Diamantina, 18 $14^{\prime} 17^{\prime \prime S}, 43^{\circ} 36^{\prime} 40^{\prime \prime W}, 1288$ m s.n.m., 5 jun. 1985 (fr.), E. Pereira 1689 (RB).

Styrax pedicellatus é reconhecida pelas flores com até $0,65 \mathrm{~cm}$ compr., apenas cinco estames e ovário com

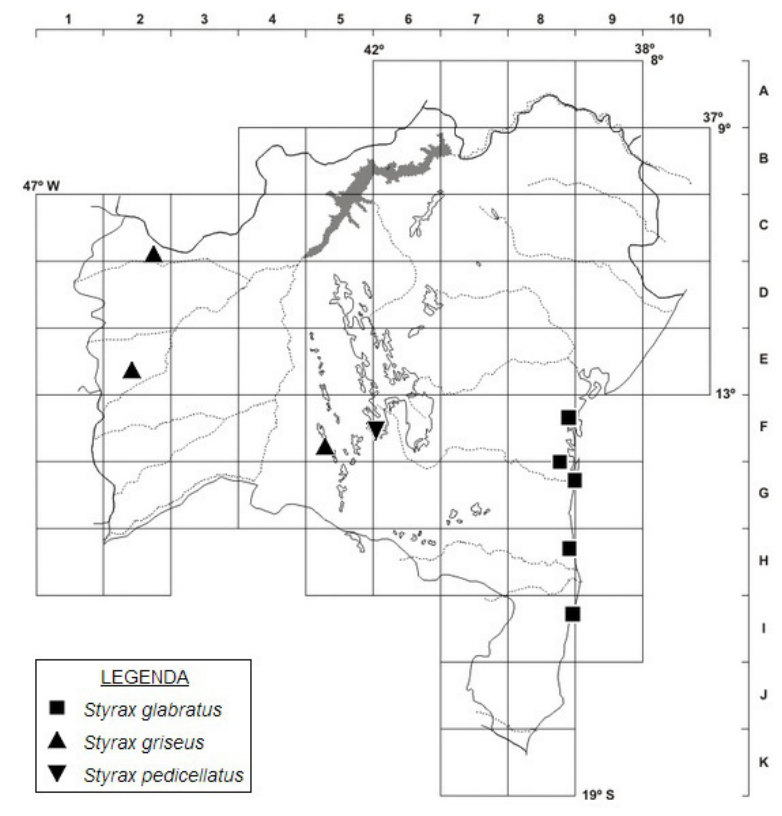

Figura 3. Distribuição geográfica de Styrax glabratus, S. griseus e S. pedicellatus no estado da Bahia.

um óvulo por carpelo. Esta espécie apresenta folhas coriáceas com margem revoluta e indumento abaxial cinéreo a dourado de tricomas com raio ca. $0,3 \mathrm{~mm}$, sendo aveludadas ao toque. Devido à presença de cinco estames, $S$. pedicellatus foi posicionada originalmente em Pamphilia Mart., gênero sinonimizado em Styrax por Wallnöfer (1997). Styrax pedicellatus é conhecida na Bahia por apenas uma pequena população aparentemente isolada no Pico das Almas, em Rio de Contas (Wallnöfer 1997).

\section{Styrax pohlii A.DC., Prodr. 8: 264. 1844.}

\section{Figuras $4 \mathrm{H}-\mathrm{I}$ e 5.}

Arvoretas ou arbustos, 3-5 m alt.; ramos estreladotomentosos, castanhos a ferrugíneos quando jovens. Folhas com pecíolo 6-11(-14) mm; lâmina 5,5-11,4 × $2-5(-6,4) \mathrm{cm}$, cartácea a subcoriácea, discolor, elíptica, estreito-elíptica a estreito-ovada, base cuneada, obtusa ou arredondada, ápice agudo a levemente acuminado, margem plana ou revoluta, nervuras primárias e secundárias salientes, terciárias levemente salientes, quaternárias impressas, face adaxial glabrescente, face abaxial densamente estrelado-tomentosa, cinérea a posteriormente acinzentada, nervuras ferrugíneas com tricomas marrons a ferrugíneos maiores esparsos na lâmina e adensados nas nervuras sobre indumento denso de tricomas cinéreos menores, raio dos tricomas 0,4-0,8 mm. Inflorescências 2-4 cm, com 2-9 flores, raque castanha a ferrugínea; pedicelo $1,5-4 \mathrm{~mm}$ compr. Flores 1,6-1,7 cm compr.; cálice 4,5-5,5 × 4-5 mm, castanho-amarelado a ferrugíneo, tricomas cinéreos, dourados e quantidade variável de tricomas ferrugíneos; pétalas $15-16 \times$ ca. $2,5 \mathrm{~mm}$; estames 10 , 

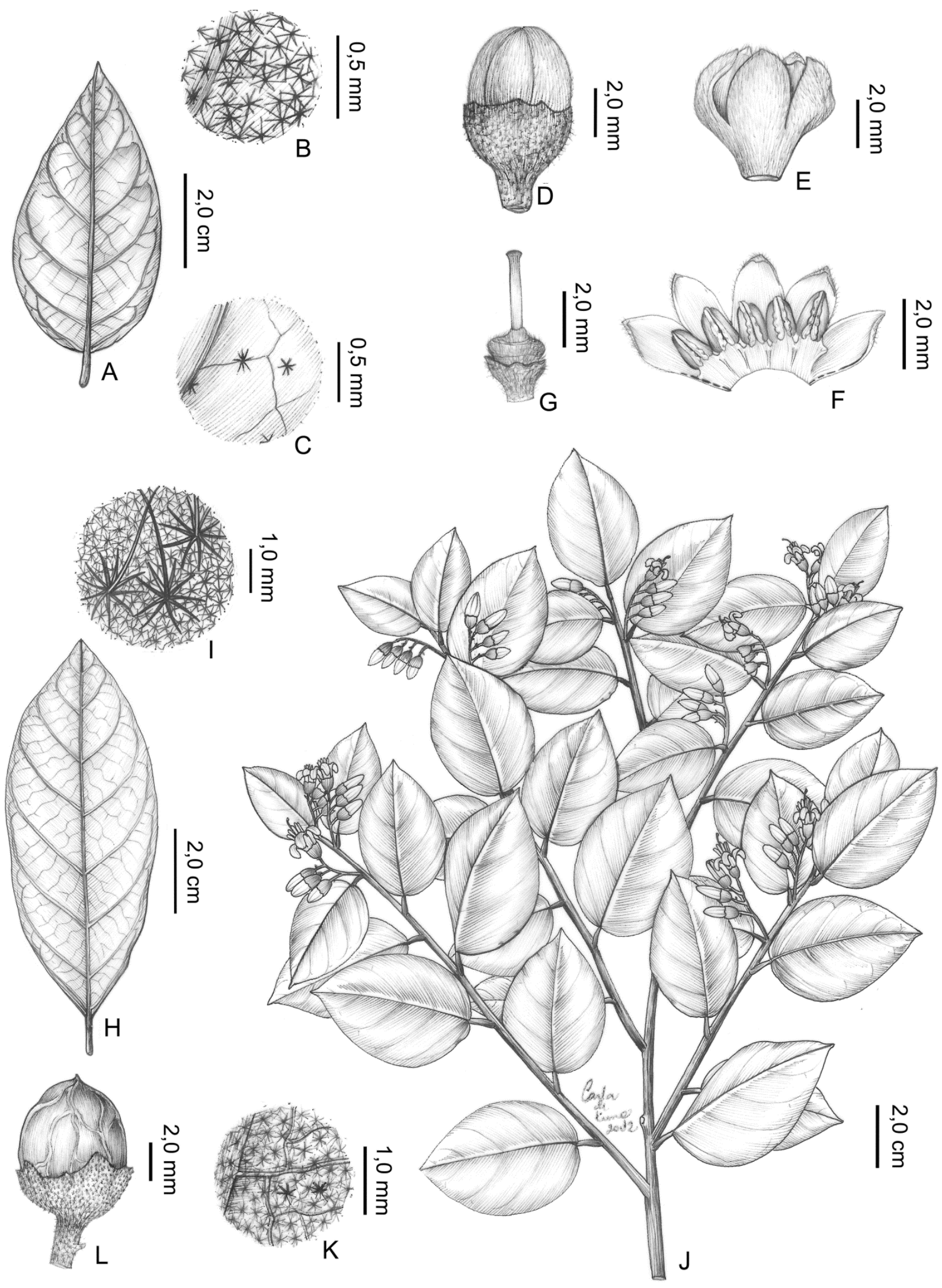

Figura 4. A-C. Styrax griseus: A- folha, face abaxial; B- detalhe do indumento da folha, face abaxial; C- detalhe do indumento da folha, face adaxial. D-G. Styrax pedicellatus: D- botão, vista lateral; E- corola; F- corola distendida com estames adnatos; G- pistilo. H-I. Styrax pohlii: H- folha, face abaxial; I- detalhe do indumento da folha, face abaxial. J-L. Styrax rotundatus: J- ramo com flores; K- detalhe do indumento da folha, face abaxial; L- fruto maduro, vista lateral. (A-C- Harley 53745; D-G- Harley 26651; H-I- Harley 25958; J-K- Souza 5; L- Conceição 1415). 
12-12,5 mm compr., filetes pubescentes, anteras 5-5,5 mm compr., pubescentes; ovário ca. 2,5 mm larg., óvulos numerosos, estilete ca. $12 \mathrm{~mm}$. Drupas 10-11× 5-6 mm, globosas a subglobosas, envolvidas até ca. $1 / 3$ pelo cálice.

Ocorre no Paraguai (Perkins 1907) e no Brasil, em ambientes úmidos e alagados associados a formações de cerrado, nos estados do Centro-Oeste e em alguns estados do Norte, Nordeste e Sudeste (Fritsch 2012). F3, F6: floresta ciliar em campo rupestre e cerrado. Coletada com flores em novembro e com frutos imaturos em abril.

Material examinado - Jaborandi, rodovia para Correntina, 13³2'42"S, 44³2'19"W, 660 m s.n.m., 19 abr. 2001 (fr.), J.G. Jardim et al. 3710 (CEPEC); Rio de Contas, Pico das Almas,

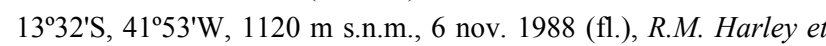
al. 25958 (CEPEC).

Material adicional examinado - BRASIL. DISTRITO FEDERAL: Reserva Ecológica do IBGE, 155'48"S, 4753'50"W, 5 jul 1989 (fl.,fr.), M.L.M Azevedo \& D. Alvarenga 228 (RB).

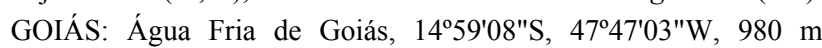
s.n.m., 7 out. 1997 (fl.), M.A. Silva et al. 3356 (RB).

Styrax pohlii é reconhecida por apresentar indumento heterogêneo na face abaxial das folhas, com tricomas ferrugíneos esparsos sobre indumento denso de tricomas cinéreos, sendo os ferrugíneos mais abundantes nas nervuras, proporcionando a coloração ferrugínea das mesmas. Os ramos jovens são caracteristicamente castanhos ou ferrugíneotomentosos e o cálice castanho-amarelado a ferrugíneo.

$\mathrm{Na}$ Flora Brasiliensis (Seubert 1868), Styrax pauciflorus A.DC. foi tratada como sinônimo de Styrax pohlii. Embora Fritsch (2012) indique que $S$. pauciflorus ocorre na Bahia, não foram observados materiais desta espécie dentre as coleções analisadas.

\section{Styrax rotundatus (Perkins) P.W.Fritsch, Novon 14:} 52. 2004.

Figuras 4J-L e 5.

Arvoretas ou arbustos, (0,2-)1-3(-5) m alt.; ramos estrelado-tomentosos, ferrugíneos ou marrom-escuros quando jovens. Folhas com pecíolo (3-)5-7 mm; lâmina 2,5-6,7 × 1,3-4,2 cm, subcoriácea a coriácea, discolor, ovada, elíptica a suborbiculada, base obtusa, arredondada, truncada ou raramente subcordada, ápice obtuso, arredondado, agudo ou levemente atenuado, margem plana ou levemente revoluta, nervuras primárias a quaternárias salientes, face adaxial glabrescente, face abaxial densamente estreladotomentosa, lâmina e nervuras ferrugíneas, posteriormente acinzentadas, com quantidade variável de tricomas ferrugíneos ou marrons sobre indumento denso de tricomas cinéreos, raio dos tricomas $0,15-0,2 \mathrm{~mm}$. Inflorescências 1,6-6 cm, 2-8(-16) flores, raque ferrugínea ou marrom; pedicelo (2,5-)4-7 $\mathrm{mm}$ compr. Flores 1-1,5 cm compr.; cálice 3,5-5(-6) × 2,5-4 mm, ferrugíneo ou marrom; pétalas $9,5-14 \times 1,5-2 \mathrm{~mm}$; estames 10, (8,5-)11,5-13 $\mathrm{mm}$ compr., filetes pubescentes, anteras $5,5-6 \mathrm{~mm}$ compr., pubescentes;

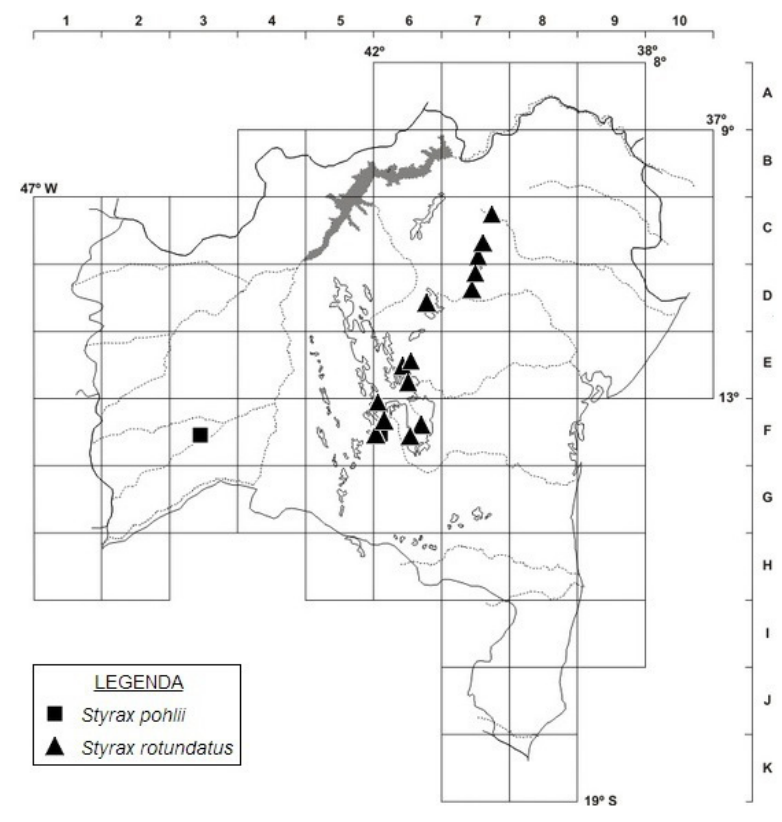

Figura 5. Distribuição geográfica de Styrax pohlii e S. rotundatus no estado da Bahia.

ovário ca. 1,5 mm larg., óvulos numerosos, estilete $(8-) 10,5-11,5 \mathrm{~mm}$ compr. Drupas 5,5-7(-8) $\times(4-) 5-6 \mathrm{~mm}$, globosas a subglobosas, envolvidas até ca. $3 / 5$ pelo cálice.

Styrax rotundatus ocorre em Minas Gerais e Bahia (Fritsch 2004b, 2012). C7, D6, D7, E6, F6: cerrado, campo rupestre e floresta estacional semidecidual. Coletada com flores e frutos por quase todos os meses do ano.

Material selecionado - Abaíra, Catolés, $13^{\circ} 20^{\prime} 38^{\prime \prime} \mathrm{S}$, 41 $1^{\circ} 50^{\prime} 15^{\prime \prime} \mathrm{W}, 1578$ m s.n.m., 22 abr. 2003 (fl., fr.), E.B. Miranda et al. 556 (HUEFS); Barra da Estiva, Serra do Sincorá, $13^{\circ} 35^{\prime} \mathrm{S}$, $41^{\circ} 27^{\prime} \mathrm{W}, 1300$ m s.n.m., 22 mar. 1980 (fl.), R.M. Harley et al. 20733 (parátipo CEPEC); Ibicoara, Cascavel, 13⒉'38"S, 41 ${ }^{\circ} 17^{\prime} 05^{\prime \prime} \mathrm{W}, 1027 \mathrm{~m}$ s.n.m., 31 jan. 2011 (fl.), H.A. Ogasawara et al. 76 (ALCB); Jacobina, Estância dos Bandeirantes, $11^{\circ} 08^{\prime} 37^{\prime \prime} \mathrm{S}$, 40²9'27"W, 873 m s.n.m., 4 jun. 2011 (fr.), N. Roque et al. 3034 (ALCB); Lençóis, Serra da Chapadinha, 12027'35"S, $41^{\circ} 26^{\prime} 25^{\prime \prime} \mathrm{W}$, 910 m s.n.m., 27 out. 1994 (fl.), A.M. Carvalho et al. 1106 (ALCB, CEPEC, HUEFS, HUESC); Miguel Calmon, Parque Estadual das Sete Passagens, $11^{\circ} 23^{\prime} 18^{\prime \prime} \mathrm{S}, 40^{\circ} 32^{\prime} 08^{\prime \prime} \mathrm{W}, 1040 \mathrm{~m}$ s.n.m., 4 abr. 2001 (fl.), N.G. Jesus et al. 1259 (ALCB, CEPEC, HUEFS, HUESC); Morro do Chapéu, Morrão, $11^{\circ} 35^{\prime} 27^{\prime \prime S}, 41^{\circ} 12^{\prime} 27^{\prime \prime} \mathrm{W}, 1270 \mathrm{~m}$ s.n.m., 16 dez. 2005 (fl.), F. França et al. 5335 (HUEFS); Mucugê, Gerais do Rio Preto, $12^{\circ} 46^{\prime}$ S, $41^{\circ} 29^{\prime}$ W, 1300 m s.n.m., 20 jun. 2005 (fr.), A.A. Conceição \& D. Cardoso 1415 (HUEFS); Palmeiras, Morro do Pai Inácio, 12³1'44"S, 41³3'32"W, 697 m s.n.m., 25 jan. 1998 (fl.), A.M. Amorim et al. 2137 (parátipos CEPEC, HUESC); Piatã, estrada Piatã - Inúbia, 130.'19"S, 41 ${ }^{\circ} 55^{\prime} 24 " \mathrm{~W}, 1370 \mathrm{~m}$ s.n.m., 24 fev. 1994 (fl.), P.T. Sano et al. 14489 (parátipo CEPEC); Pindobaçu, Serra da Paciência, 1041'35"S, 40²2'45"W, $1200 \mathrm{~m}$ s.n.m., 10 abr. 2001 (fr.), H.P. Bautista et al. 3111 (ALCB, CEPEC,

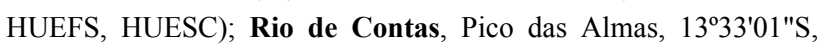
41 ${ }^{\circ} 57^{\prime} 01 " \mathrm{~W}, 1250-1600$ m s.n.m., 26 fev. 2006 (fl.), J.L. Paixão et al. 727 (CEPEC, HUEFS); Saúde, Cachoeira do Paiaió, 1054'02"S, 
40²6'55"W, 680 m s.n.m., 4 abr. 1996 (fl.), E. Woodgyer et al. 2836 (ALCB, CEPEC); Senhor do Bonfim, Serra da Jacobina, $10^{\circ} 16^{\prime} \mathrm{S}, 40^{\circ} 15^{\prime} \mathrm{W}, 1100$ m s.n.m., 28 fev. 1974 (fl.), R.M. Harley 16561 (parátipos CEPEC, RB).

Styrax rotundatus pode ser reconhecida por apresentar folhas pequenas, até $6,7 \mathrm{~cm}$ compr., coriáceas, comumente suborbiculares ou ovadas, com face abaxial ferrugíneo-tomentosa e nervuras quaternárias salientes. Styrax rotundatus foi incialmente tratada como variedade de $S$. martii e, recentemente, elevada para o nível de espécie por Fritsch (2004b).

\section{AgRADECIMENTOS}

Os autores agradecem a Carla Lima pelas ilustrações. AMA é financiado pelo CNPq (Bolsa PQ 306992/2012-4; Edital Reflora 563548/2010-0) e RCA é financiado pelo CNPq (Bolsa AT-NM 372220/2013-4). A execução dessa pesquisa foi viabilizada pelo $\mathrm{CNPq}$ através da concessão de Bolsa IC (509166/2010-5) para RCA.

\section{REFERÊNCIAS}

APG III 2009. An update of the angiosperm phylogeny group classification for the orders and families of flowering plants. Botanical Journal of Linnean Society 161: 105-121.
Fritsch, P.W. 1997. A revision of Styrax (Styracaceae) for Western Texas, Mexico and Mesoamerica. Annals of the Missouri Botanical Garden 84: 705-761.

Fritsch, P.W. 1999. Phylogeny of Styrax based on morphological characters, with implications for biogeography and infrageneric classification. Systematic Botany 24(3): 356-378.

Fritsch, P.W. 2004a. Styracaceae. In: Smith, N., Mori, S.A., Henderson, A., Stevenson, D.W. \& Heald, S.V. (eds), Flowering Plants of the Neotropics. Princeton University Press, New Jersey, p. 362-363.

Fritsch, P.W. 2004b. New species and taxonomic changes in Styrax (Styracaceae) from South America. Novon 14(1): 43-57.

Fritsch, P.W. 2012. Styracaceae. Lista de Espécies da Flora do Brasil. Jardim Botânico do Rio de Janeiro. Disponível em: http://floradobrasil.jbrj.gov.br/2012/FB014891; acesso em 01 out. 2012.

Fritsch, P.W., Morton, C.M., Chen, T. \& Meldrum, C. 2001. Phylogeny and Biogeography of the Styracaceae. International Journal of Plant Sciences 162(6 Suppl.): S95-S116.

Loeuille, B.; Fritsch, P.W. \& Pirani, J.R. 2008. Flora da Serra do Cipó, Minas Gerais: Styracaceae. Boletim de Botânica da Universidade de São Paulo 26(2): 175-182.

Perkins, J. 1907. Styracaceae. In: Engler, A. (ed), Pflanzenreich IV, v. 241. Verlag von Wilhelm Engelmann, Leipzig, p. 1-111.

Seubert, M. 1868. Styracaceae. In: Martius, C.F.P. von \& Eichler, A.G. (eds), Flora Brasiliensis, v. 7, p. 182-198.

Wallnöfer, B. 1997. A Revision of Styrax L. section Pamphilia (Mart. ex A.DC.) B.Walln. (Styracaceae). Annalen des Naturhistorischen Museums in Wien 99b: 681-720.

\section{LISTA DE EXSICATAS}

Almeida, J. 172 (4); Alves, M. 2203 (5); Amaral, D.L. 42 (5); Amaral, I.L. 992 (5); Amorim, A.M.A. 1409 (4), 1801, 2137 (8), 2936 (2), 4017 (8), 7227 (9); Assis, J.S. 84 (5); Azevedo, M.L.M. 228 (7), 1356 (5); Barreto, M. 724 (7); Barreto, V. 62 (8); Barros, W.D. 914 (1); Bautista, H.P. 414, 941 (8), 1265 (2), 3111 (8), 3207 (2), 4015 (8); Becker, R.M. 4 (5); Brazão, J.E.M. 202 (8); Brito, H.S. 159 (4); C.M.M. 222 (1); Cardoso, D. 335 (2), 407 (8); Carvalho, A.M. 1043, 1106 (8), 1826, 1966 (2); Carvalho-Sobrinho, J.G. 695 (2); Castro, R.M. 991 (8); Cid, C.A. 4410 (5); Coelho, M.M. 494 (1); Conceição, A.A. 207, 1415, 1681, 2219, 2352 (8); Conceição, S.F. 288, 538 (2); Cordeiro, I. 8152 (6); Costa, A.L. s.n. ALCB 9033 (8); Costa, J. 363 (8); Duarte, A.P. 5005 (1); Eupunino, A. 116 (4); Farias, R. 279 (5); Farney, C. 3881 (8); Ferreira, V.S. 15 (8); Fiaschi, P. 2509 (4); Fonseca, M.L. 3070 (3); Forzza, R.C. 1170 (8); França, F. 2796 (8), 2861 (8), 2950, 3167, 3938, 4296 (2), 5335 (8), 5453 (2), 5924 (8); Funch, R. 10 (8); Furlan, A. 2120 (8), 3321 (6); Ganev, W. 302, 446, 1564 (2), 1589 (8), 1774, 1974, 2032, 2993, 3392 (2); Gasson, P. 5906 (8); Giulietti, A.M. 6865 (8); Gonçalves, L.M.C. 173 (2); Guedes, M. L. 707, 139, 1551 (8), 2128, 2571 (2), 4978, 6749 (8), 7668 (2), 9827, 10733 (8), 10382 (2), 11302 (8), 11716 (2), 11717 (8), 13040 (2), 13084, 14205, 15155, 16712 (8), s.n. ALCB 25144, s.n. CEPEC 62405 (2); Hage, J.L. 2328 (8); Harley, R.M. 5565 (2), 15476,15651 (8), 15656 (2), 16561 (8), 18629 (2), 19270, 19913, 20733 (8), 21318 (2), 22775, 24283, 24464 (8), 25958 (7), 26651 (6), 28236 (2), 51212 (8), 53745 (5), 54219 (6), 54382 (2), 54932 (6); Hatschbach, G.M. 62031 (5); Hind, D.J.N. 50293 (8); Jardim, J.G. 59 (8), 3045 (4), 3710 (7); Jesus, A.R. 20 (8); Jesus, N.G. 1259 (8); Klein, R.M. 889, 1019, 1683 (1); Kral, R. 72879 (8); Kuhlmann, M. 3436 (7); Lima, M.P.M. 135 (5); Lordêlo, R. $57-311$ (8); Loureiro, D.M. 51 (2); Martinelli, G. 9654 (4); Mattos Silva, L.A. 507 (4); Meireles, J.E. 703 (2); Melo, E. 1161, 1234, 1292 (8); Melo, M.R.F. 206 (7); Mendonça, R.C. 3422 (5); Miranda, E.B. 556 (8); Mori, S.A. 9658 (2), 10846 (4), 12894 , 13538, 14380, 14473 (8), 16657 (3); Mota, N.F.O. 1092 (5); Nadruz, M. 2336 (1); Nascimento, F.H.F. 164, 197 (8), 354 (2), 385 (8); Nascimento, J.G. 280 (8); Nunes, T.S. 253 (8); Ogasawara, H.A. 76 (8); Oliveira, A. 116 (2); Oliveira, J. 16 (5); Orlandi, R.P. 106 (5); Paixão, J.L. 727 (8); Palma, M. s.n. R 194196 (7); Pastoré, U. s.n. RB 178966 (5); Paula-Souza, J. 5147 (2); Pereira, A. 1758 (8); Pereira, E. 1689 (6); Pereira, J. s.n. HUEFS 106552 (2); Pereira, R.C.A. 1 (8), 2 (8); Philcox, D. 4589 (5); Pinheiro, R.S. 1380 (4); Pinto, G. s.n. ALCB 8936 (2); Pirani, J.R. 5424 (8), 51347 (2); Queiroz, E.P. 3076 (5); Queiroz, L.P. 1909 (8), 4256 (8), 9188,9541 (2), 13316 (8); Rapini, A. 1516 (2); Ratter, J.A. 1284 (5); Ribeiro, P.L. 147 (8); Ribeiro, T. 196 (2); Roque, N. 960, 3034 (8); Saar, E. 4940 (2); Sakuragui, C.M. 15069 (6); Sano, P.T. 14489 (8); Santos, J.S. 91, 148 (8); Santos, T.S. 2344 (2); Santos, V.J. 467 (8); Sarmento, A.C. 842 (8); Scariot, A.O. 499 (5); Schwarke 8297 (6); Secco, R.S. 460 (5); Serrão Neto, A.C. 4 (8), 17 (8), 19 (8), 20 (2), 25 (8); Shepherd, G.J. 3945 (6); Silva, A.S.L. 3979 (5); Silva, M.A. 3356 (7); Silva, M.G. 2995 (5); Silva-Pereira, V. 23 (8); Smith, L.B. 12043 (1); Sobral, M. 7589 (8); Sousa, L.A. 241 (8); Souza, A. 1399 (5); Souza, E.B. 939 (8), 1434 (2); Souza, E.R. 5 (8), 194 (2); Souza, P. s.n. ALCB 21190 (8); Souza, V.C 22660 (8); Stannard, B. 5366 (2); Stapf, M.N.S. 320 (2); Stradmann, M.T.S. 1154 (2); Thomas, W.W. 9665 (2), 12886 (8); Woodgyer, E. 2789, 2836 (8). 